\title{
تعليم الحوار باستخدام وسيلة الكلمات في اللوح (Word Wall)
}

\author{
رحمى أولياء فطري \\ ديديه وحي الدين \\ عادة الدراسات العليا بجامعة سونان غونونج جاتي الإسلامية الحكومية باندونج \\ rachmaassaif@gmail.com \\ dedihwahyudin@gmail.com
}

\section{ملخص}

إن الأغراض لهذا البحث هي معرفة تحصيل التلاميذ الدراسي قبل استخدام وسيلة الكلمات في اللوح وبعد استخدامه في تعليم الحوار لتلاميذ الصف الثاني في مدرسة العرفان العالية الإسلامية بورواكرتا ومعرفة الأثر من استخدامه إلى ترقية تحصيل النلاميذ الدراسي فيه. والطريقة المستخدمة في هذا البحث هي الطريقة التجريبية بتصميم الاختبار القبلي والاختبار البعدي لجموعة واحدة. أما الأساليب لمجح البيانات فهي المقابلة والملاحظة والدراسة المكتبية والاختبار . ومن النتائج المحصولة من هذا البحث أن تحصيل التلاميذ الدراسي قبل استخدام وسيلة الكلمات في اللوح حصل على طبقة منخفضة. وهذا كما دلت عليه قيمة المتوسط على قدر ع • ، هـ وتحصيل التلاميذ الدراسي بعد استخدام وسيلة الكلمات في اللوح حصل على طبقة عالية،

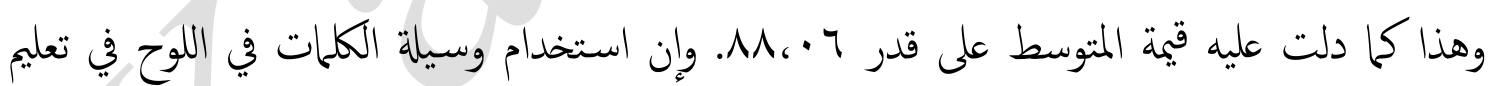

$$
\begin{aligned}
& \text { الحوار يؤثر في ترقية تحصيل التلاميذ الدراسي ومستوى التاثثير على قدر ا\٪٪ } \\
& \text { الكلمات المفناحية: تعليم الحوار، الوسيلة، الكلمات في اللوح }
\end{aligned}
$$

\begin{abstract}
The purpose of this study was to find out the value of students in learning Arabic alhiwar before and after using the word wall media in second-graders at Madrasah Aliyah Al-Irfan Purwakarta. The method used in this study is an experimental method with the design of one group pre-test and post-test design. The techniques used in data collection are interviews, observations, and tests. The results of this study note that the value of students in learning Arabic al-hiwar before using word wall media obtained an average yield of 55,04 and the value of students in learning Arabic al-hiwar after using word wall media obtained an average yield of 88,06. Thus, the use of word wall media in learning Arabic language al-hiwar has an influence in increasing the value of
\end{abstract}


students by a percentage of $71 \%$.

Keywords: Learning, Media, Word Wal

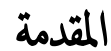

إن اللغة هي أداة اتصالية يستخدمحا الناس للتكلم بينهم وبين الفرد في جميع أنحاء العالم. باللغة يكن للناس تبادل الأفكار والآراء والتعبير عن ما فيهم. اللغة هي نظام اعطباطي لرموز صوتية تستخدم لتباد الأفكار والمشاعر بين أعضاء جهاعة لغوية متجانسة'. اللغة العربية هي إحدى اللغات الأجنبية التي لها دورهام في الحياة اليومية. فإنها تنبني أن تكون مفهومة بشكل واضح عند مدرس اللغة العربية وإنكان بعض التلاميذ يزعمون أن مواد اللغة العربية صعبة. حيث كانت اللغة العربية المواد الصعوبة عندهم بالنسبة إلى اللغة الأجنبية الأخرى، إن اللغة العربية في الحقيقة غير صعبة كما رأوا وبخاصة لهوّلاء المسلمين في إندونسيا، وكانوا متعودين على استخدامحا في عبادته. فهذا ينبني لجميع مدرسي اللغة العربية أن يفهموا الهدف الأخير من تعليم اللغة العربية هو استيعاب التلاميذ مهارات اللغة العربية من حمارة الاستماع والكلام والقراءة والكنابة.

التعليم هو عملية منظمة للوصول إلى هدف معين. خير التعليم هو ما إذا جرى التعليم فاعلية حتى يصل إلى هدف مقصود. إن هدف التعليم للوصول إلى نجاح التلاميذ. فلذلك تحصيل هذا الهدف يجب يدعمه عدة العوامل من الطرق والوسيائل والأساليب التي يستفيدمنها المدرس في سير التعليم. إن وسيلة التعليم أداة من أدوات التعليم. وقد كانت واسطة في نقل معلومات التعلم ومعانيها وماصدر منها إلى المستمع حتى يكون تعامل التعليم والتعلم وهي الواسطة التي تستخدم لإعانة نقل

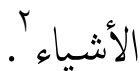

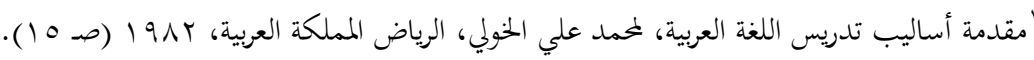

${ }^{2}$ Azhar Arsyad, Media Pembelajaran (Jakarta: PT Rajagrafindo Persada, 2013), 3.

2 | Kalamuna: P-ISSN: 2655-4267, E-ISSN: 2745-6943 
(رهى أولياء فطري، ديديه وحي السين) تتعليم الحوار باستخدام...

الوسائل هي عنصر تأثر في عملية النعليم. لوجود الوسائل أوعدما في عملية التعليم يؤدي إلى

ترقية جودة نتيجة التعلم.كانت وسيلة التعليم تزيد على فعالية الاتصال بين المعلم والمتعلم. وكذلك تكون وسيلة التعليم فعالية لتزقية دافعية التلاميذ ثُّ إنجازهم.

وسيلة التعليم المتنوعة لن تستخدم كاملا في وقت واحد في أنشطة التعلم، لذلك يحتاج إلى اختيار الوسيلة المناسبة معتمدا على معايرها. وإن المعايير التي يجب مراعاتها في اختيار الوسيلة التعليم منها: (1) دقة الوسيلة بهدف التدري؛ (Y) دع عن محتوى المواد النعليمة؛ (r) سهولة الحصول على يلى الوسائل؛ (ع) عمارة المعلمين في استخداها؛ (0) الوقت المتاح لإستخداها؛ (7) وفقة لمستوى تفكير

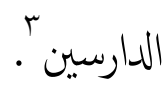

تبعا لتطور الوسائل التعلمية هناك وسائل متنوعة كالمجلة والكناب والرسالة. ومن الوسائل التى يستخدما المدرس في تعليم الحوار هي وسيلة الكلمات في اللوح. وهي مجموعة المفردات والكلمات المنظمة

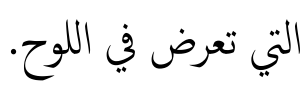

بناء على البيانات المحصولة من الملاحظة الأولى، كان تعليم اللغة العربية وخاصة في تعليم الحوار لايزال أقل ابتكارا. وفي تعليم اللغة العربية لتلاميذ الصف الثاني مدرسة العرفان العالية الإسلامية بورواكرتا

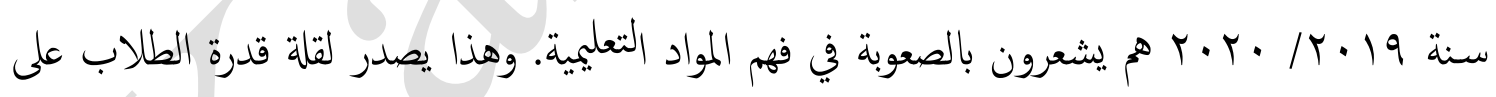
استيعاب المفردات في تعلم اللغة العربية بل لا تزال منخفضة وصعوبة وكذلك قلة المدرس في استخدام وسيلة التعليم المناسبة.

نظر إلى المشكلات السابقة، تجب معالجها ومن الوسائل التعلمية التى تعتبرها الكاتبة تجعل التلاميذ قاديرين على تعلم الحوار هي وسيلة الكلمات في اللوح. إن الوسائل التعلمية مهمة لنجاح تعلم الحوار. هذه الوسيلة يراد التلاميذ أن يقدروا على فهم الحوار، وإعطاء الفرصة إلهم في ترقية قدرتم بأنسهم. وأن

\footnotetext{
${ }^{3}$ Nanang Kosim, Media Pembelajaran Bahasa Arab (Bandung: CV Fajar Media, 2013), 18.
} 
تكون مناسبة لجعل التلاميذ راغبين في عملية التعلية. ومن وظائف الطريقة هي تكوين البيئة الجديدة والمفرحة، تستخدم وسيلة الكلمات في اللوح في تعليم اللغة العربية خاصة في تعليم الحوار. لأن استخدام هذه الوسائل تجعل التلاميذ قادرين على الحوار بالمواد المناسبة المستفادة. ولإجابة هذه المشكلة تريد الكلتبة القيام بدراسة تجريبة عن قدرة التلاميذ في الحوار. فلذلك

قدمت الكاتبة الموضوع تعليم الحوار باستخدام وسيلة الكلمات في اللوح (Word Wall). من البحوث السابقة المناسبة منها: (1) تطبيق وسيلة الكلمات في اللوح (Word Wall) في June كournal of ABDIMAS Vol. 19 No. 1) تدريس مهارات القراءة لبناء ثقافة القراءة عند الطفل. 2015) بقلم نورايني عباس، هارتاتي، أتيب نورهاريني لقسم تأهيل المعلم الابتدائى، كلية التربية والتعليم، بالجامعة الحكومية سيارانج؛ (r) تعليم المفردات العربية باستخدام وسيلة الكلمات في اللوح (Word Wall) (دراسة تجريبية على تلاميذ الصف العاثر في مدرسة المحمدية الثانوية المهنية ب يوجياكرتا). بقلم أنا ريسكا سري؛ (r) استخدام وسيلة الكلمات في اللوح (Word Wall) في تعليم المفردات الأندونيسية لغير الناطقين بها في المرحلة المتوسطة للمعهداللغوي يوجياكرتا. (رسالة الكلية اللغة والفن، بالجامعة الحكومية يوجياكرتا، با · ب) بقلم نور إنتان رنجانيز رحماواتي. والفرق بين البحوث السابقة والبحث الذي تقوم به الكانبة، أن الهدف من البحث الذي تقوم به الكاتبة هو التلاميذ ولكن الهدف من البحث في المجلة الأولى هو المعلمون. والفرق بين هذه البجلة وما تبحث عنه الكاتبة هو من ناحية الموضوعات والمتغيرات وطرق البحث. ستستخدم الكاتبة هذه الوسيلة في تعليم اللغة العربية خاصة في تعليم الحوار، وتحصيل التلاميذ الدراسي فيه يكون المتغير الصادي في هذا 
(رهى أولياء فطري، ديديه وحي الدين) تعليم الحوار باستخدام...

إن الحوار أو المسمى بالتعبير الشفهى هو أداة الإنسان في اتصال بغير معبرا عما يريد، أو متحدثا عما يزول بخاطره، أو معبرا عما فى نفسه من مشاعر واحساسات. وبعبارة أخرى أن الحوار هو نوع من الحديث بين شخصين أو فريقين يتم فيه تداول الكلام ببنها بطريقة متكفئة يستأثربه أحدها دون الآخر، ويغلب عليه الهدوء والبعد عن الخصومة والتعصب؛. والحوار هو طريقة من طرق التواصل الذي هدفه المراجعة في الكلام للوصول إلى الصواب. الحوار وتبادل الحديث بين طرفين أو أكثر يريدكل من المتحاورين الوصول إلى أهدف. والتعبيرالشفهي هو أهم الغاية المنشودة من دراسة اللغة، لأنه وسيلة الإفهام، وكذلك أنه وسيلة لاتصال الفرد بغيره، وأداة لتقوية

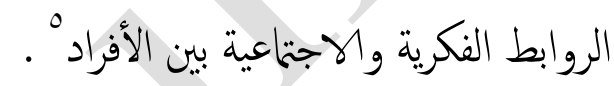
من المعلوم أن الحوار العربي عند المتعلم الاجنى له أهمية كثيرة. وإن أهمية الحوار العربي كما يليج : ( ) تكين التلاميذ من التعبير عها في نفوسهم، أو عحا يشاهدونهم بعبارة سليمة صحيحة؛ ؟) توسيع دائزة أفكار التلاميذ؛ r) تزويد التلاميذ بما يعوز هم من المفردات والتراكيب الجيدة؛ ع) تعويد التلاميذ التفكير المنطقى وترتيب الأفكار وربط بعضها ببعض؛ 0) إعداد التلاميذ المواقق الحيوية التى تتطلب فصاحة

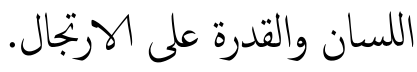
قال عبد الرحمن إبراهيم إن سمات الحوار ما يليل : ( ) جملة قصيرة؛ ب) تحكي المواقف اليومية الحقيقية؛ ؟) قابل للمحاكاة والتطبيق؛ ع) جملة قد لا تكون مترابطة؛ 0) مما يتيح لمعد الكتاب حرية اختيار المفردات والتراكيب يخدم الجانب التصالي للغة؛ 7) الجانب التشويقي فيه كير؛ V) استخدمه يشعر الدرس بتقدمه في تعلم اللغ؛ م) يتيح للدراس ممارسة ما تعلم فعاليا خارج الصف.

\footnotetext{
${ }^{4}$ Henry Guntur Tarigan, Berbicara Sebagai Suatu Keterampilan Berbahasa (Bandung: Angkasa, 2008), 200.

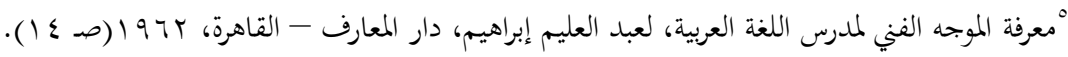

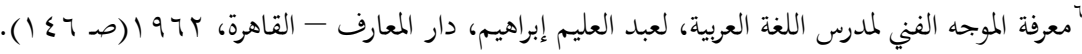

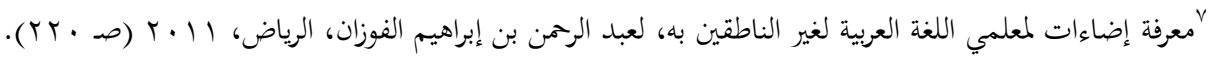




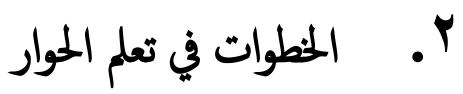

$$
\text { قال عبد الرحن إبراهيم إن الخطوات في تعلم الحوار ما يلي؛ }
$$

() التحية : الطلاب لتحية الإسلام، وتلقى إجاباته؟؛ ؟) إعداد السبورة؛ ؟) المراجعة؛ ع)

التمهيد للدرس؛ 0) المفردات الجديجة؛ 7) الاستماع والكتب مغلقة؛ V) الاستماع والكتب مفتوحة؛ م) الاستاع والإعادة؛ 9) اطلب من الطلاب أداء الحوار جاعيا، وعن طريق المجموعات، وثنائة والكتب مفتوحة؛ • (1) اطلب من الطلاب أداء الحوار جاعيا، وعن طريق المجموعات، وثنائة والكتب مغلقة.

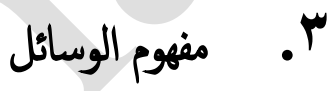

الوسائل لغة ما يتوصل به الإنسان إلى شيء، أو يتغرب به إلي غيره. إن الوسيلة هي الواسطة التي بلغة المبلغ إلى مقابله ج والوسائل هي أداة أووسيلة اتصالية مثل الجريدة والجملة والمذياع والتلفيزيون والأفلام والموسيقي '.

الوسائل التعلمية هي ألة أو طريقة مستخدمة لمؤثرة اتصالية والتفاعل بين المدرس والتلاميذ في العملية التزبوية والعملية التعليمية في المدرسة' ' وإن الوسائل المعينة كل مايستعين به المعلم على تفهيم التلاميذ من الوسائل التوضيحية المختلفة" آ. ومن المفهوم الآخر أن الوسائل المعينة أو الوسائل النعلمية هي مايلجأ إليه المعلم من أدوات وأبحزة ومواد لتسهيل عملية التعليم والتعلم وتحسنيهاوتعزيزها؟”.

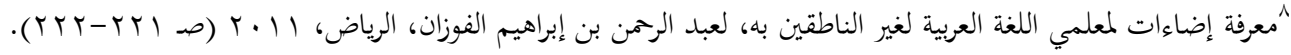

${ }^{9}$ Nanang Kosim, Media Pembelajaran Bahasa Arab (Bandung: CV Fajar Media, 2013), 4.

${ }^{10}$ Azhar Arsyad, Media Pembelajaran ( Jakarta: CV Fajar Media, 2013), 448.

11 Daryanto, Media Pembelajaran Peranannya Sangat Penting Mencapai Tujuan Pembelajaran (Yogyakarta: Gava Media, 2010), 201.

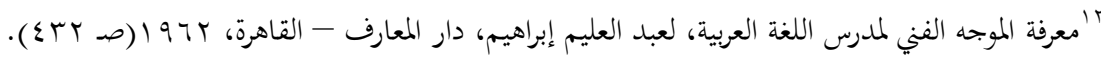

${ }^{13}$ Yudhi Munadi, Media Pembelajaran Sebuah Pendekatan Baru (Jakarta: GP Press Grup), 32.

6 | Kalamuna: P-ISSN: 2655-4267, E-ISSN: 2745-6943 


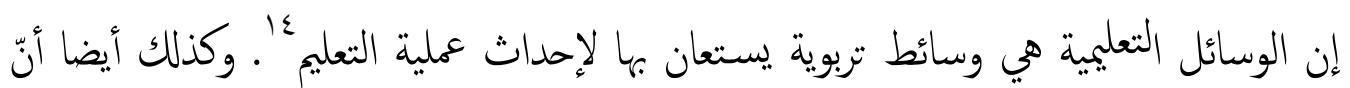

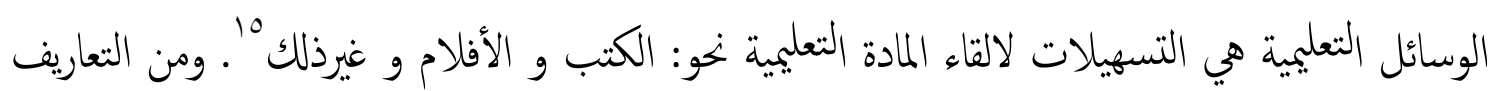
السابقة تستنتج الكاتبة أن الوسائل هي كل أداة يستخدها المعلم لتحسين عملية التعليم.

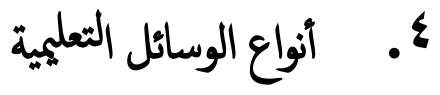

تتنوع الوسائل التعلمية وتتطور الأزمان، فنها ماتعتمد على اللغة اللفظية أو المسموعة، ومنهاما تعتمد على الصور والرموز والتسجيلات الصوتية، ومنها ما تعتمد على الصور المتحركة والتلفاز وغيرها. ويرى الفوزان أن وسائل التعليمية تنقسم إلى مجموعات وذلك حسب الحاسة التي تخاطها، وهي" أ) الوسائل التعلمية بشكل المواد المطبوعة أو المرسومة، مثل: الكنب، والصورة التعلمية، والرسومات والخزائط، واللوحات النعلمية، والشفافيات، والبطاقات، والرموز.

ب) الوسائل التعليمية بشكل المواد السمعية البصرية الثابتة، مثل: أفلام ثابتة، وأشرطة صوتية وأسطوانات.

ج) الوسائل التعلمية بشكل المواد السمعية البصرية المتحركة، مثل: أفلام متحركة، وأشرط الفيديو،

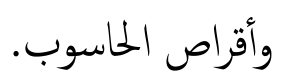

\section{وكانت الوسائل التعلمية تنقسم إلى ثلاثة أقسام "}

أ) الوسائل البصرية هي آلة وسيلة البصرية تشتمل على وسائل الإيضاح مثل المواد العلمية والإنسان والوقيع والحوائج المقلدة وغيرهم منها الصورة، الأفلام الثابتة والمتحركة، السبورة، الخرائط، الكرة الأرضية، اللوحات والبطاقات، الرسوم البيانات، المناذج والعنات، المعارض والمتحاف.

\footnotetext{
${ }^{14}$ Uril Bahrudin, Mahārat Al Tadrīs (Malang: UIN Maliki Press, 2011), 154.

${ }^{15}$ Hujair AH Sanaky, Media Pembelajaran Interaktif-Inovatif (Kaukaba: Yogyakarta, 2013), 52.

${ }^{16}$ Abdurrahaman Ibrahim Al Fauzan, Idhaāt Li Mu'allimī Al Lughah Al 'Arabiyyah Li Ghairi Al Nāthiqina Bihā (Riyadh: Al Mamlakah Al Arabiyyah As Su'udiyyah, 2011), 158.

${ }^{17}$ Muhammad Ali Al Khuli, Asālību Tadrīs Al Lughah Al 'Arabiyyah (Beirut: Al Farazdaq al Tijariyyah, 1982), 165.
} 
ب) الوسائل السمعية هو الأدوات التي تعمد على السع وتشتمل: الإذاعة المدرسية الداخلية، الراديو،

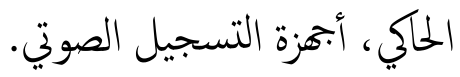

ج) الوسائل السمعية البصرية هي تضم الأدوات التي تعتمد على حستي السمع والبصر معا مثل: الأفلام المتحركة والناطقة، الأفلام الثابنة والمصحوبة بتسجيلات صوتية، مسروح العرئس، التلفاز، جهاز

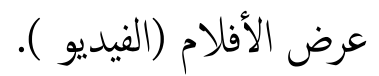

وتقسم الوسائل التعليمة إلى قسمين ": وسائل حسية هي ماتوثرفي القوى العقلية بوساطة

الحواس وسائل لغوية وهي ما تؤثر في القوى العقلية بوساطة الألفاظ.

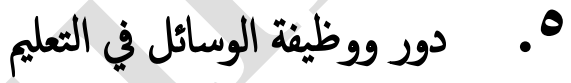

من المعروف أن الوسائل لها دور وفوائد في عملية التعليم والتعلّم، وإن دور الوسائل التعلمية في

تحسين النعليم مما يلي 19

أ) إثراء التعليم، إن الوسائل التعليمة تلعب دورا جوهريا في إثراء التعليم وتوسيع خبرات المتعليم وتيسير بناء المفاهيم وتخطي الجدود الجغرافية الطبيعية باستخدام وسائل اتصال متنوعة تعرض الوسائل التعليمة بأساليب مشيرة ومشوفة وجذابة.

ب) تحتيق اقتصادية التعليم ويقصد بذلك جعل عملية التعليم اقتصادية بدرجة أكبر من خلال زيادة نسبة التعليم إلى تكفيته، فالهدف الرئيس للوسائل التعليمة هو تحتيق أهداف التعلم قابالة للقياس بمستوى فعال بأقل قدرة من التكفة في الوقت والجهد والمصادر.

ج) المساعدة على استثارة الاهتمام بالتلميذ وإشباع حاجته للنعلم حيث يكتسب التلميذ من خلال استخدام الوسائل التعلمية الخختلفة بعض الخبرات التى تثير اهتمامه وتحيق أهدافه، وكلما كانت

\footnotetext{
${ }^{18}$ Ibrahim, Op.Cit,. 432.

${ }^{19}$ Bahrudin, Mahārat Al Tadrīs. Op.Cit,. 155-157.

8 | Kalamuna: P-ISSN: 2655-4267, E-ISSN: 2745-6943
} 
(رهى أولياء فطري، ديديه وحي الدين) تعليم الحوار باستخدام...

الخبرات التعلمية التى يمر بها المتعلم أقرب إلى الواقعية أصبح لها معنى ملموس وثيق الصلة بالأهداف التى يسعى التلميذ إلى تحقيقها والرغبات التى يتوق إلى إثباعها. د) المساعدة على زيادة خبرة التلميذ مما يجعله أكثز استعدادا للتعلم وباستخدام وسائل تعلمية متنوعة يكتسب التلميذ خبرات مباشرة تجعله أكثر استعدادا للتعلم، مما ساعد على جعل تعلم التلميذ فى أفضل صورة.

ه) المساعدة على اشتراك جميع حواس المتعلم فى عملية التعلم إن اشتراك جميع الحواس فى عمليات التعليم يؤدى إلى ترسيخ وتعميق هذا التعلم والوسائل التعلمية تساعد على اشتراكـ جميع حواس المتعلم، مما يساعد بقاء أثر التعلم. و) المساعدة فى زيادة مشاركة التلميذ الإيهابية فى اكتساب الخبرة حيث تنمى الوسائل التعليمية قدرة التلاميذ على التأمل ودقة الملاحظة واتباع النفكير العلمي للوصول إلى حل المثكلات. وهذا الأسلوب يؤدي بالضرورة إلى تحسين نوعية التعلم ورفح الأداء عند التلاميذ.

\section{7. وسيلة الكلمات في اللوح (Word Wall Media)}

إن وسيلة الكلمات في اللوح (Word Wall) هي من الوسائل التعلمية التي تقدر على ترقية قدرة التلاميذ على استيعاب المفردات وممارستها في الحوار. وإن وسيلة الكلمات في اللوح هي مموعة المفردات والكلمات المنظمة التي معروضة بأحرف كبيرة وإلصاقها بلوح أو بجدار الفصل، وهي تسير إلى محفظات دائمة من تعليم اللغة الذي يقوم به التلاميذ'·. وكانت وسيلة الكلمات في اللوح من الوسائل التعليمية التي يجب استخدامحا ولا يتم عرضها أو مشاهدتها حسب. وصممت هذه الوسيلة على ترقية أنشطة بموعة الدراسة واشتراك التلاميذ في صنعها بنشاط. وترجى هذه الوسيلة على ترقية فهم المفردات للتلاميذ وهم يستطيعون أن يجروا بالحوار المدروس

${ }^{20}$ Janiel M Wagstaff, Teaching Reading and Writing With Word Walls (USA: Scholastic Inc), 15. 
داخل الفصل. وباستخدام هذه الوسيلة يكن التلاميذ أن يتطوروا محاراتهم في الاستماع والكلام والقراءة

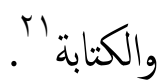

الكلمات في اللوح عبارة عن مجموعة تفاعلية من الكلمات أو أجزاء من الكلمات المستخدمة لندريس

المفردات والإملاء والمراسلات الصوتية والحروفية وغير ذلك. وتستخدم هذه الوسيلة كأداة لنعليم اللغة. تعد الكلمات في اللوح عرضًا منظمًا ومستمًرًا للكلمات الرئيسية التي توفر مرجمًا بصريًا للطلاب خلال وحدة دراسية أو فصل دراسي. يتم استخدام هذه الكلمات باستمرار من قبل المعلمين والتلاميذ خلال بمحوعة متنوعة من الأنشطة. هناك طرق لجعل اللوح كلمة فعالة وعملية واستظهر بسهولة. الكلمات في اللوح عبارة عن وسائط تفاعلية في الفصل الدراسي للدفاع عن تعلم الاستماع والتحدث والقراءة والكتابة r

هناك أغراض إضافية لاستخدام الكلمات في اللوح. أولاً، تدع هذه الوسيلة تطوير مفردات التلاميذ. في الفصل الدراسي الخاص بمنطقة المحتوى، يمكن استخدامحا لتطوير المفردات الأكاديمية. توفر الكلمات في اللوح (Word Wall) أمثلة على الكلمات، والتي تبرز المفاهيم الصعبة. يقوم العديد من المعلمبن بإنشائها التي تدع تعلم التلاميذ للكلمات عالية التردد. يستطيع النلاميذ تضمين الكلمات المهمة بالنسبة لمم. وأخيرًا، توفر الكلمات في اللوح مساحة للتلاميذ لفرز وتصنيف الكلمات والعبارات. وكان معظم المدرس يستخدم هذه الوسيلة في تعليم المفردات. وترجو هذه الوسيلة أن ثرقي قدرة التلاميذ على استيعاب المفردات وفهمها دون الاعتماد على المعجم أو معنى الكلمات التي قدمها المعلم. وفي هذا البحث ستقوم الكاتبة بهذه الوسيلة في تعليم الحوار. بالإضافة إلى معرفة المفردات ومعانيها، يمكن التلاميذ أن يمارسوا تلك المفردات في عبارات بسيطة في تعليم الحوار.

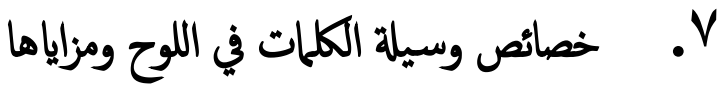

\footnotetext{
${ }^{21}$ Ibid., 16

${ }^{22}$ Kelly Gilbert, word wall Journal (Waymart: Universal Publishing, 2003), 8.

10 | Kalamuna: P-ISSN: 2655-4267, E-ISSN: 2745-6943
} 
(رهى أولياء فطري، ديديه وحي الدين) تعليم الحوار باستخدام...

يختلف كل معلم عند تحديد كيفية عرض الكلمات في اللوح (Word Wall) وترتيها واستخدامحا

داخل الفصل، ولكن هناك بعض الخصائص الشائعة ”َّ

أ) تجمع عبارة عن مجموعات من الكلمات المناسبة للتطور للدراسة من قبل التلاميذ في الفصل. ب) يتم اختيار الكلمات لأغراض تعلمية محددة. ج) تجمع المجموعات التزاكية؛ كما يتم تقديم كلمات جديدة؛ تبقى كلمات مألوفة لمزيد من الدراسة. د) توفر الأنشطة والتحدث عن الكلمات في اللوح سقالات للمحادثة تعمل على تنظيم الطرق هـ) التي يدرس بها التلاميذ ويفكرون ويستخدمون الكلمات.

و ) تساعد الكلمات على اللوح بمثابة سقالات بصرية تساعد الثلاميذ مؤقتًا في القراءة المستقلة.

ومن مزايا وسيلة الكلمات في اللوح منها : ( ) لدع تدريس مبادئ عامة مهة حول الكلمات؛ ؟ )

تطوير مجموعة أساسية متنامية من الكلمات التي تصبح جزءًا من القراءة والكتابة؛ ب) لجعل التلاميذ مارسة اللغة العربية للتواصل وتعويدها؛ ع) لإنشاء مجموعة متنوعة من لعبة اللغة باستخدام الكلمات في اللوح؛ 0) يكن للمدرسين اختيار موضوع المفردات أو الحوار أو عنصر قواعد اللغة. يمارس جميع التلاميذ بطريقة تفاعلية وبسيطة في تعلم اللغة، مثل: مطابقة الكلمات وتكوين الكلمات.

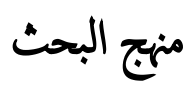

كان المدخل المستخدم في هذا البحث هو المدخل الكمي (Quantitative Entrance). يعتبر

المدخل الكمي أحد المداخل المستخدمة في تنفيذ الأبحات العلمية، ويحتوي في طياته على أدوات دراسية يككن عن طريقها الوصول إلى واقع رقي له مدلوله. ويعرف بأنه أحد طرق القياس التي يتم استخداما في

\footnotetext{
${ }^{23}$ Neci Selvia Fitri, "The Application of Learning Media Word Wall to Improve Japanese Vocabulary of $11^{\text {th }}$ Grade Students in SMAN 9 Pekanbaru" dalam Journal online Mahasiswa Fakultas Keguruan dan Ilmu Pendidikan Universitas Riau (JOM FKIP UNRI), vol . 1, No. 1, (Oktober 2017), 6.
} 
الأبحاث والدراسات العلمية لاختبار الفرضيات ومن ثم تطبيق النظريات والمفاهيم المكتسبة على أرض

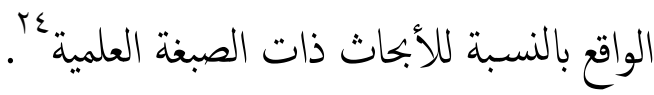

تستخدم الكاتبة هذا المدخل لأن البيانات في هذا البحث تحتوي على البيانات الكمية. وهي البيانات التي تأخذ شكل رقي مثل الإحصاءات والنسب المؤوية. طريقة البحث هي طريقة موضوعية تتبع لدراسة ظاهرة من الظواهر، بقصد تشخيصها وتحديد أبعادها ومعرفة أسبابها وطرق علاجحا والوصول إلى ننائُ عامة يمكن تطبيقها، فالطريقة فن تنظيم الأفكار ، سواء للكشف عن حقيقة فير معلومة لنا، أو لاثبات حقيقة نعرفها ب. الطريقة التى تستخدما الكاتبة في هذا البحث هي الطريقة التجريبية بتصميم مجموعة واحدة الاختبار القبلي - الاختبار البعدي (one group pre test post test design في المجموعة الواحدة. الاختبار هو أداة التي تعطى للأفراد للحصول على الأجوبة المقصودة شفويا أو كتابيا أو فعليا.

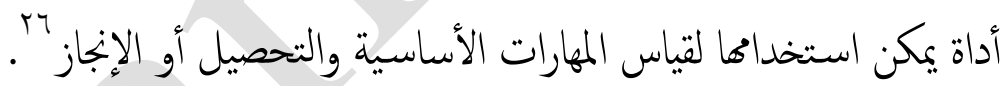
تقوم الكاتبة بالاختبار القبلي ويعطي الأسئلة إلى الفصل التجربي لمعرفة تحصيل التلاميذ الدراسي في تعليم الحوار قبل استخدام وسيلة الكلمات في اللوح (Word Wall). وبعد ذلك تقوم الكاتبة بالعلاج باستخدام وسيلة الكلمات في اللوح (Word Wall). وفي الاختبار البعدي تعطي الكاتبة الأسئلة إلى الفصل التجربي لمعرفة تحصيل التلاميذ الدراسي في تعليم الحوار بعد استخدام تلك الوسيلة. وصفت تصميم البحث على النحو التالي :

\footnotetext{
${ }^{24}$ Sugiyono, Metode Penelitian Kuantitatif Kualitatif Dan R\&D (Bandung: Alfabeta, 2016), 15.

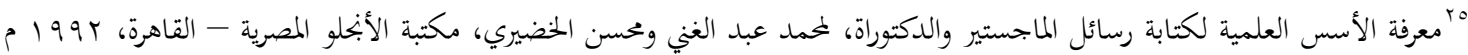
.09 ( $)$ ${ }^{26}$ Suharsimi Arikunto, Prosedur Penelitian Suatu Pendekatan Praktik (Jakarta:PT. Rineka Cipta, 2010), 266.
} 
(رومى أولياء فطري، ديديه وجي الاين) تعليم الحوار باستخدام...

\begin{tabular}{|l|l|l|}
\hline & العلاج & \\
\hline $\mathrm{O}_{2}$ & $\mathrm{X}$ & $\mathrm{O}_{1}$ \\
\hline
\end{tabular}

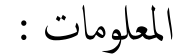

الاختبار القبلي قبل العلاج = O

Word Wall) العلاج باستخدام وسيلة الكلمات في اللوح X

البعار البعدي بعد العلاج

أما الأساليب لمحع البيانات فهي المقابلة والملاحظة والدراسة المكتبية والاختبار من الاختبار القبلي والبعدي.

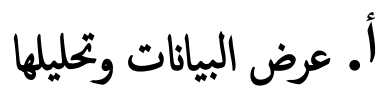

ا ـ واقعية تحصيل التلاميذ الدراسي قبل استخدام وسيلة الكلمات في اللوح (Word Wall) لمعرفة واقعية تحصيل التلاميذ الدراسي قبل استخدام وسيلة الكلمات في اللوح في مدرسة

العرفان العالية الإسلامية بورواكرتا قدمت الكلتبة خمسة عشر سؤالا اختباريا بتجريب الكاتبة إلى ال تلميذا من الصف الثاني في هذا البحث.

اعتمد تنظيم أسئلة الاختبار القبلي على ثلاثة مؤشرات وهي تمكين التلاميذ من النطق عا في

نص الحوار جيدا وتمكين التلاميذ من معرفة معنى المفردات في النص وتكين التلاميذ من فهم نص الحوار. كما هو المكتوب في أغراض البحث أن الكاتبة تريد أن تعرف تحصيل التلاميذ الدراسي قبل استخدام وسيلة الكلمات في اللوح وبعد استخدامه في تعليم الحوار لتلاميذ الصف الثاني في مدرسة العرفان العالية الإسلامية بورواكرتا. ولتحقيقها، قد قامت الكانبة بالاختبار القبلي الصف الثاني في مدرسة العرفان العالية الإسلامية بورواكرتا. 
وبعد القيام بالاختبار القبليي وجدت الكاتبة النتائج الآتية: ( ) يعرف أن المجموع من الاختبار

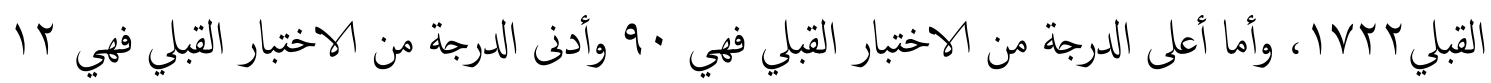
وقيمة المتوسط ع ·00 ندل على درجة منخفضة لأها تقع بين •0 - 09 في معيار التفسير؛ r) ومن

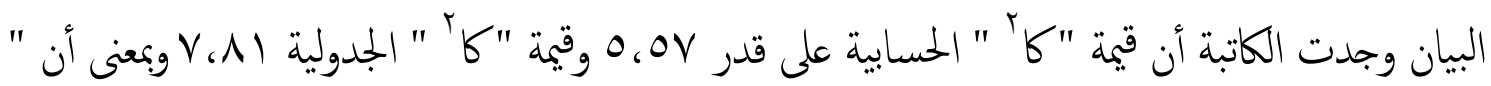
كَ' " الحسابية أصغر من قيمة "كَ' " الجدولية. وبهذا يعرف أن البياتات لتحصيل التلاميذ الدراسي قبل استخدام وسيلة الكلمات في اللوح (Word Wall) في تعليم الحوار لها توزيع متعدل. ץ · علية استخدام وسيلة الكلمات في اللوح (Word Wall) في الفصل التجريبي وبعد معرفة واقعية تحصيل التلاميذ الدراسي قبل استخدام وسيلة الكلمات في اللوح في مدرسة العرفان العالية الإسلامية بورواكرتا بتقديم أسئلة الاختبار القبلي على خمسة عشر سؤالا اختباريا بتجريب الكاتبة إلى اس تلميذا من الصف الثاني في هذا البحث. تقوم الباحثة بالعلاج باستخدام وسيلة الكلمات في اللوح. ويكن توضيح الخطوات قبل عملية النعليم فيم يلى: (أ) تحديد الأهداف النعلمية؛ (ب) تصميم إعداد التدريس؛ (ج) تحديد المادة الدراسية؛ (د) تحديد حجم المجموعات؛ (ه) تعيين التلاميذ في المجموعات. وأما أثناء التعليم تجري عملية تعليم الحوار باستخدام وسيلة الكلمات في اللوح بالخطوات التالية: أ) تقديم التحية ب) التهيد، تشرح المعلمة أهداف التعليم والإجراءات وتطرح بعض الأسئلة ومراجعة الوحدة أو الدروس السابقة. ج) تشرح المعلمة المادة التعلمية بايجاز. د) تقسم المعلمة مجموعات صغيرة متنوعة منسجمة بناء على ننائج الاختبار القبلي. تقوم الباحثة بتقسيم التلاميذ إلى بمموعات صغيرة يتزاوح عدد أفراد المجموعة الواحدة ما بين ب-ع تلاميذ، ويقوم كل مجموعة

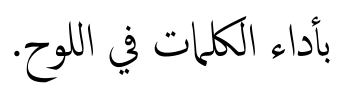




$$
\begin{aligned}
& \text { (رهى أولياء فطري، ديديه وحي الدين) تعليم الحوار باستخدام... } \\
& \text { هـ يلصلق التناميذ الوسيلة في جدار الفصل. } \\
& \text { و ) يقوم التلاميذ بالحوار وفقا لنص الحوار الذي كتب في اللوح. } \\
& \text { ز) التقو.يم: يجري التلاميذ الحوار بدون النظر. }
\end{aligned}
$$

هكذا تم استخدام وسيلة الكلمات في اللوح في تعليم الحوار لدى التلاميذ بمدرسة العرفان العالية الإسلامية بورواكرتا. ويستغرق موضوع واحد حصتين كما هو مكتوب في الجدوال، وللباحثة ثلاثة موضوعات، فيكون التطبيق داخل الفصل في ستة حصص دون أربع حصص للاختبارين القبلي والبعدي.

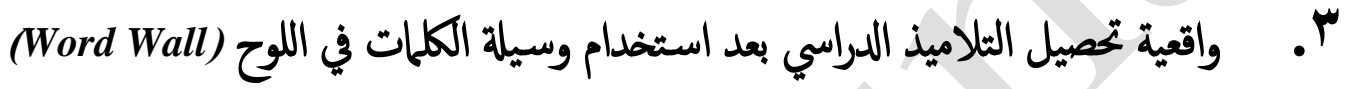
قامت الكانبة بعملية النعليم والنعلم في الفصل التجربي لنعليم الحوار باستخدام وسيلة الكلمات في اللوح (Word Wall)، ولمعرفة واقعية تحصيل التلاميذ الدراسي بعد استخدام وسيلة الكلمات في اللوح في مدرسة العرفان العالية الإسلامية بورواكرتا قدمت الكاتبة خمسة عشر سؤال اختباريا في الاختبار البعدي بتجريب الكاتبة إلى اب تلميذا من الصف الثاني في هذا البحث. واعتمد تنظيم أسئلة الاختبار البعدي على ثلاثة مؤشرات وهي تمكين التلاميذ من النطق عما في نص الحوار جيدا وتكين التلاميذ من معرفة معنى المفردات في النص وتمكين النلاميذ من فهم نص الحوار. وبعدما قامت الكاتبة بالاختيار البعدي إلى التلاميذ في تعليم الحوار فتحصل على النتائج الآتية: يعرف أن أعلى درجة النتيجة من الاختبار البعدي هي . . أوأدنى درجة النتيجة من الاختبار البعدي هي •م ومجموع النتائُ من الاختبار القبلي هي • • لأها تقع بين • V - Vq في معيار التفسير. وإضافة إلى ذلك، عرفت الكانبة أن نتيجة التلاميذ في تعليم الحوار في مدرسة العرفان العالية الإسلامية باستخدام وسيلة الكلمات في اللوح (Word Wall) تدل على ترقية نتيجة التلاميذ فيها بالمقارنة مع دون هذا الوسيلة من قبل. 
Kalamuna, Vol. 1. No. 1 Juli 2020, 1 - 18

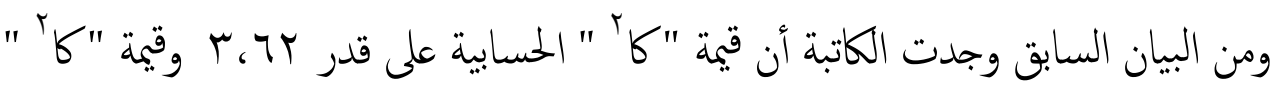

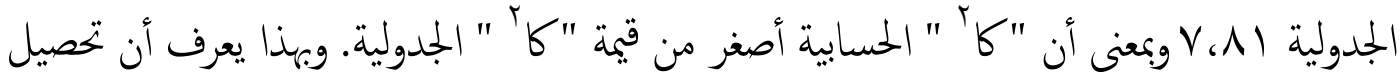

التلاميذ الدراسي بعد استخدام وسيلة الكلمات في اللوح Word Wall) في تعليم الحوار له توزيع متعدل. ع. واقعية ترقية تحصيل التلاميذ الدراسي بعد استخدام وسيلة الكلمات في اللوح (Word Wall) في

$$
\text { تعليم الحوار }
$$

تقوم الكاتبة بالبحث لمعرفة حقيقة ترقية تحصيل التلاميذ الدراسي بعد استخدام وسيلة الكلمات

في اللوح (Word Wall) في تعليم الحوار للتلاميذ الصف الثاني في مدرسة العرفان العالية الإسلامية

بورواكرتا بالخطوات الآتية: ( ) تعيين مج لكُّد بالجدول (Y) تعيين المتوسط من الهختلاف بينها (ب) تعيين قيمة (ت) الحسابية (ع) وتعيين قيمة "د" بالمعادلة الآتية:

$$
\text { د = نتيجة الاختبار النهائي - نتيجة الاختبار لإبندائي }
$$

أقصى الدرجة الممكنة - نتيجة الهختبار لابتدائي

ومن البيان السابق وجدت الكاتبة أن أعلى الدرجة من قيمة "د" بr، • وأدنى الدرجة من قيمة

"د" وقيمة المتوسط لV ل · · فوجدت الكاتبة قيمة التأثير لتحصيل التلاميذ الدراسي في تعليم الحوار بعد استخدام وسيلة الكلمات في اللوح (Word Wall) على قدر اV، · حيث تدل على درجة عالية لأن هذه

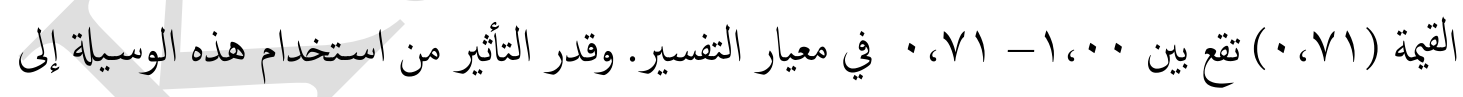
ترقية تحصيل التلاميذ الدراسي في تعليم الحوار حصل على قيمة IV ٪ وهي في طبقة عالية حسب معيار

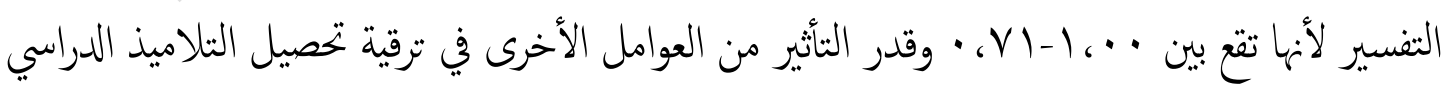
في تعليم الحوار حصل على قيمة وب ٪ فهي تأتي من الطريقة التعلمية، أوالمدرس، أوالدوافح، أوالبيئة اللغوية أوغيرها.

خاتمة البحث 
بعد القيام بالبحث في مدرسة العرفان العالية الإسلامية بورواكرتا وتحليل بياناته تقدم الكاتبة النتأُج الآتية: (1) إن تحصيل التلاميذ الدراسي قبل استخدام وسيلة الكلمات في اللوح (Word Wall) في الصف الثاني في مدرسة العرفان العالية الإسلامية بورواكرتا حصل على طبقة منخفضة. وهذا كما دلت عليه قيمة المتوسط على قدر ع.،00 لأهها تقع بين مدى 09-09 معيار التفسير. (Y) إن تحصيل التلاميذ الدراسي بعد استخدام وسيلة الكلمات في اللوح (Word Wall) في الصف الثاني في مدرسة العرفان العالية الإسلامية بورواكرتا حصل على طبقة عالية. وهذا كما دلت عليه قيمة المتوسط على قدر 7 >، 14 لأها تقع بين مدى 99-•1 معيار التنسير. (r) إن استخدام وسيلة الكلمات في اللوح (Word Wall) في تعليم الحوار يؤثر في ترقية تحصيل التلاميذ الدراسي وهذا يتحقق بكون قيمة (ت) الحسابية = دی أكبر من

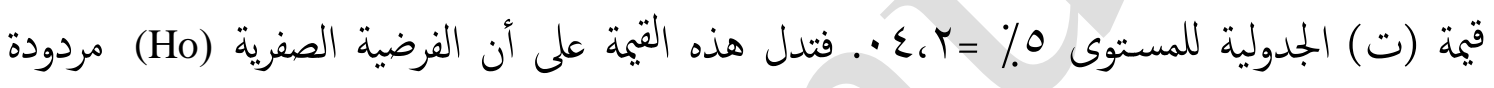
والفرضية المقترحة (Ha) مقبولة وهذا يعنى أن هناك تأثيرا ظاهرا في تحصيل التلاميذ الدراسي في تعليم الحوار بعد استخدام وسيلة الكلمات في اللوح (Word Wall). وقدر التأثير من استخدام هذا الوسيلة إلى ترقية تحصيل التلاميذ الدراسي في تعليم الحوار حصل على قيمة اV٪٪. وهي في طبقة عالية حسب معيار

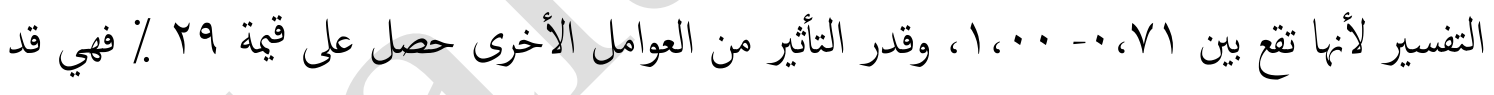
تأتي من الطريقة التعليمة، أوالمدرس، أوالدوافع، أوالبيئة اللغوية أوغيرها.

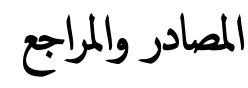

Abdul Ghani, Muhammad. 1992. Al-Ususu al-Ilmiyyah lì kitābati Rosāil al-Mājistīr wa al-Dukturoh. Kairo: Maktabah al-Anjalu al-Misriyyah.

AH Sanaky, Hujair. 2013. Media Pembelajaran Interaktif-Inovatif. Kaukaba: Yogyakarta.

Al Fauzan, Abdurrahaman Ibrahim. 2011. Idhaāt Li Mu'allimī Al Lughah Al 'Arabiyyah Li Ghairi Al Nāthiqūna Bihā. Riyadh: Al Mamlakah Al Arabiyyah As Su'udiyyah.

Al-Khuli, Muhammad Ali. 1982. Asālīb Tadrīs al-Lughah al-Arabiyyah. Riyadh alMamlakah al-Arabiyyah. 
Arikunto, Suharsimi. 2010. Prosedur Penelitian Suatu Pendekatan Praktik. Jakarta:PT. Rineka Cipta.

Arsyad, Azhar. 2013. Media Pembelajaran. Jakarta: PT Rajagrafindo Persada.

Bahrudin, Uril. 201. Mahārat Al Tadrīs. Malang: UIN Maliki Press, 2011.

Daryanto. 2010. Media Pembelajaran Peranannya Sangat Penting Mencapai Tujuan Pembelajaran. Yogyakarta: Gava Media.

Fitri, Neci Selvia. 2017. "The Application of Learning Media Word Wall to Improve Japanese Vocabulary of $11^{\text {th }}$ Grade Students in SMAN 9 Pekanbaru” dalam Journal online Mahasiswa Fakultas Keguruan dan Ilmu Pendidikan Universitas Riau (JOM FKIP UNRI), vol . 1, No. 1.

Gilbert, Kelly. 2003. Word Wall Journal. Waymart: Universal Publishing, 2003.

Ibrahim, Abdul Alim. 1968. Al Muwajjih Al Fanniy Li Mudarrisii Al Lughah Al 'Arabiyyah. Kairo: Daar al Ma'arif.

Kosim, Nanang. 2013. Media Pembelajaran Bahasa Arab. Bandung: CV Fajar Media.

Munadi, Yudhi. 2011. Media Pembelajaran Sebuah Pendekatan Baru. Jakarta: GP Press Grup.

Sugiyono. 2016. Metode Penelitian Kuantitatif Kualitatif Dan R\&D. Bandung: Alfabeta.

Tarigan, Henry Guntur. 2008. Berbicara Sebagai Suatu Keterampilan Berbahasa. Bandung: Angkasa.

Wagstaff, Janiel M. Teaching Reading and Writing With Word Walls. USA: Scholastic Inc. 